\title{
Mortality tempo-adjustment: Theoretical considerations and an empirical application ${ }^{\star}$
}

\author{
Marc Luy \\ University of Rostock, Institute for Sociology and Demography Ulmenstrasse 69, \\ 18057 Rostock, Germany. E-Mail: email@marc-luy.de
}

Summary. The number of scholars following the tempo approach in fertility continues to grow, whereas tempo-adjustment in mortality generally still is rejected. This rejection is irrational in principle, as the basic idea behind the tempo approach is independent of the kind of demographic event. Providing the first empirical application to a substantial problem, this chapter shows that mortality tempo-adjustment can paint a different picture of current mortality conditions compared to conventional life expectancy. An application of the Bongaarts and Feeney method to the analysis of mortality differences between western and eastern Germany shows that the eastern German disadvantages still are considerably higher and that the mortality gap between the two entities began to narrow some years later than trends in conventional life expectancy suggest. Thus, the picture drawn by tempo-adjusted life expectancy fits the expected trends of changing mortality and also the self-reported health conditions of eastern and western Germans better than that painted by conventional life expectancy.

\section{Introduction}

One of the main goals of quantitative demography is the derivation of period measures with a clear and distinct meaning to analyze demographic developments in time as well as current demographic conditions in different populations. Since more than a century demographers have been assuming to know how to provide correct calculations and interpretations of period measures, such as the total fertility rate (TFR) or life expectancy at birth $\left(e_{0}\right)$. Both are summary measures and have the purpose to represent current fertility and mortality conditions respectively, standardized for the given age composition of populations driving the number of observed events and thus the values of crude rates.

\footnotetext{
* Great part of this chapter is reprinted from "Mortality tempo-adjustment: An empirical application" by Marc Luy, Demographic Research Vol. 15, 2006.(C)2006 Max-Planck-Gesellschaft, reprinted with permission
} 
In a series of studies, Bongaarts and Feeney (1998, 2002, in this volume p. 11 and p. 29) recently have claimed that summary measures such as these should not only be standardized for age but also for tempo effects that arise whenever demographic conditions are changing. In their most recent study, Bongaarts and Feeney (in this volume p. 29) define a tempo distortion as an "inflation or deflation of a period quantum or tempo indicator of a life-cycle event, such as birth, marriage, or death, resulting from a rise or fall in the mean age at which the event occurs". Introducing the idea with corresponding formulae for tempo-adjustment, Bongaarts and Feeney stirred the world of demographers and divided their community into tempo supporters and tempo opponents. Despite existing critics (e.g., Van Imhoff and Keilman, 2000; Kim and Schoen, 2000; Van Imhoff, 2001; Smallwood, 2002; Schoen, 2004; Keilman, 2006), the number of scholars following the tempo approach in fertility continues to grow (see e.g., Lesthaeghe and Willems, 1999; Kohler and Philipov, 2001; Philipov and Kohler, 2001; Zeng Yi and Land, 2001, 2002; Goldstein et al., 2003; Sobotka, 2003, 2004a, 2004b; Winkler-Dworak and Engelhardt, $2004)^{2}$. However, Bongaarts and Feeney's successive work on mortality tempo effects still is generally rejected (see Guillot, 2003b, in this volume; Le Bras, in this volume; Wachter, in this volume; Wilmoth, 2005; Rodríguez, in this volume).

The rejection is irrational in principle, as the basic idea behind the tempo approach is independent of the kind of demographic event ${ }^{3}$. The idea of adjusting period life expectancy for tempo effects is as follows. When deaths are postponed to increasingly later ages, the number of deaths occurring in a given period is thinning out. For example, if every death in a given year were to be postponed by six months, there would be only half as many deaths observed in that year as one would have expected if there had been no postponement at all. Because death rates would decline at all ages, life expectancy would in-

\footnotetext{
${ }^{2}$ Winkler-Dworak and Engelhardt (2004) applied the tempo approach to the analysis of first marriage. From a methodological point of view, their work belongs to the papers dealing with tempo effects in fertility since the demographic logic behind the analysis of first marriages is identical to the analysis of first births.

${ }^{3}$ Bongaarts and Feeney's paper on mortality tempo is based on a paper published by them earlier and entitled "On the quantum and tempo of fertility". Following the idea presented in that paper, the most common critcisms of the mortality tempo approach holds that the quantum of mortality is necessarily one, and that life expectancy itself is a pure tempo measure and thus cannot be adjusted for tempo effects (Guillot, 2003b; Wachter, in this volume; Wilmoth, 2005; Rodríguez, in this volume). Note, however, that tempo effects are not necessarily connected to a quantum. Tempo generally affects period rates and the quantum is impacted by tempo effects only if the period rates are used to estimate the demographic quantum, such as is done with the TFR. When period rates are used to derive any other demographic measures, then these measures are affected by tempo distortions. It does not matter whether they contain a quantum component or not, as is the case in period life expectancy.
} 
crease by a larger amount, many times the half a year that was actually added to the length of life in that period. Tempo-adjustment produces a period measure of longevity that changes only by the amount of lifetime by which deaths were postponed, and as such is a potentially useful tool for demographers ${ }^{4}$. It has already been shown that in a given situation of mortality decline, i.e. the mean age at death increases, life expectancy calculated from age-specific death rates during the period of changing mortality conditions is higher than life expectancy calculated from age-specific death rates under stationary mortality conditions at the end of this transition (Bongaarts and Feeney, 2002, in this volume p. 29; Feeney, 2003; Horiuchi, in this volume). An illuminating paper about the consequences of such biases on the interpretation of period data was written by Vaupel (2002), who called for a distinction between "life expectancy at current rates" and "life expectancy at current conditions" 5 .

It seems that tempo effects impact current period measures for mortality significantly, as they do with fertility measures. In the actual discussion on mortality tempo, this aspect is given no consideration: the published papers solely deal with theoretical and technical questions, while empirical applications are used exclusively to compare different measures of period mortality conditions and to demonstrate their properties against the background of historical mortality trends (besides the Bongaarts and Feeney papers mentioned above, see e.g. Vaupel, 2002, in this volume p. 93; Feeney, 2003, in this volume; Guillot, 2003b, in this volume; Bongaarts, in this volume; Le Bras, in this volume; Wachter, in this volume; Wilmoth, 2005; Goldstein, in this volume; Rodríguez, in this volume). Empirical applications to a substantive problem of mortality differentials are, however, missing so far. An interesting aspect - although not explicitly mentioned by the authors - of the initial mortality tempo paper of Bongaarts and Feeney (2002) is that the variance in life expectancy between the US, Sweden, Japan, and France decreases from 3.4 years according to conventional life expectancy to only 1.7 years according to tempo-adjusted life expectancy. Applying the Bongaarts and Feeney method to mortality differences between eastern and western Germany, I will show that adjusting period life expectancy for tempo effects paints a different picture of mortality trends and of differences between these two regions than conventional tempo-unadjusted calculations. I will conclude that the results of tempo-adjusted life expectancy provides a better fit to the expected trends

\footnotetext{
${ }^{4}$ The author thanks an anonymous referee of this paper for his or her suggestion to include this example in order to describe the basic idea of mortality tempoadjustment.

${ }^{5}$ In the paper mentioned, Vaupel (2002) regarded the distortions inherent in the current mortality rates as a consequence of the changed timing of death resulting from the effects of heterogeneity rather than from the effects of mortality tempo. Regardless of the different views on the origin of distortions in period mortality rates, Vaupel's message applies universally to all kinds of demographic period measures.
} 
of changing mortality, and also to self-reported health conditions of eastern and western Germans.

First, however, I will demonstrate how tempo effects impact period life tables and why they should be seen as distortions.

\section{How mortality tempo affects period life expectancy}

Inspired by an example in an unpublished paper of Feeney (2003) with the apt title "Mortality tempo: a guide for the skeptic", I use a simple illustration to demonstrate the idea of tempo effects in mortality. Consider a population A in which all births occur intermittently at intervals of 0.2 years and in which all deaths taking place during some base year occur at exactly the midpoint of a single year of age. Suppose that, at the end of the base year, age at death within a certain age group begins to increase linearly at the rate of 0.2 years per year for all persons, and cedes increasing at the end of the year. The Lexis diagram in Figure 1a shows this scenario for age 62 as an example. The life lines of each cohort are represented by an arrow moving through time and age. In base year t0, all deaths at age 62 happen exactly at age 62.5. During year $\mathrm{t} 1$, the age at death increases linearly with the given annual rate, from 62.5 to 62.7 . The latter level is reached in year $\mathrm{t} 2$ and remains constant from then on. Assume further that the annual numbers of births in the population have been constant and that the proportion of deaths at a certain age is constant over all cohorts (meaning unchanged mortality conditions until base year t0). The two assumptions imply that each dot in Figure 1a represents the same number of deaths and that each arrow represents the same number of persons surviving until age 62.5. Let us assume that 20,000 individuals of each cohort reach age 62 and that 1,000 of them die at this age. Thus, according to the old mortality conditions until year t0 there are 5,000 annual deaths at age 62 . The age-specific death rate for age 62 in year t0 is then given by 5,000 deaths divided by 97,500 risk years lived:

$$
M_{62, t 0}^{A}=\frac{5,000}{97,500}=0.05128 .
$$

The number of risk years lived can easily be derived. If all individuals survived until age 63 , the number of risk years lived was 100,000 since each individual lived exactly 1 person year at age 62 . Since the 5,000 deceased individuals live only 2,500 person years at age 62 , the total number of risk years lived reduces to 97,500 .

Now it is important to see what happens with the number of deaths in year $\mathrm{t} 1$, the year of changing mortality. The five cohorts in t1 reaching age 62.5 , the exact age at which those who do not survive the given age group die according to the old conditions, are marked with the letters A to E. Thus, cohort $\mathrm{A}$ is the oldest cohort reaching age 62.5 in year t1 and cohort $\mathrm{E}$ is the youngest. Due to assumed changes in mortality conditions during year t1, the 


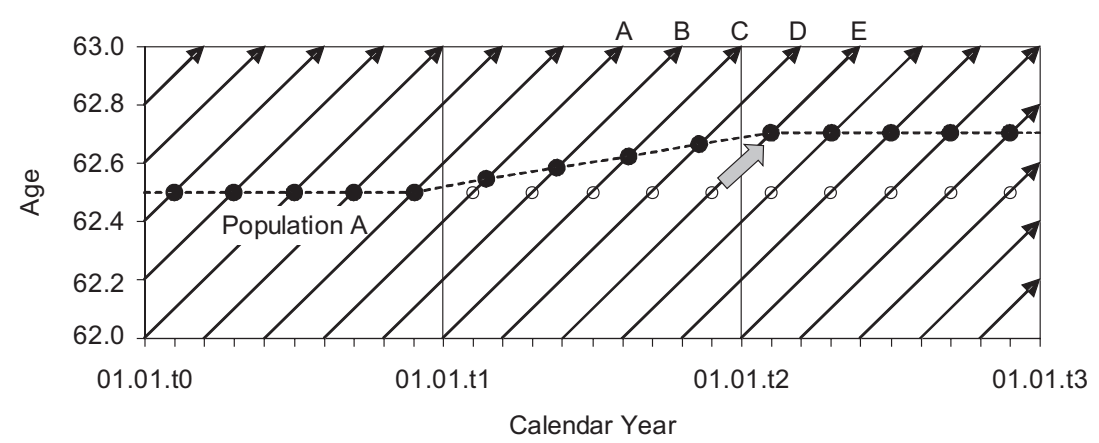

(1a) a population with decreasing mortality in year t1

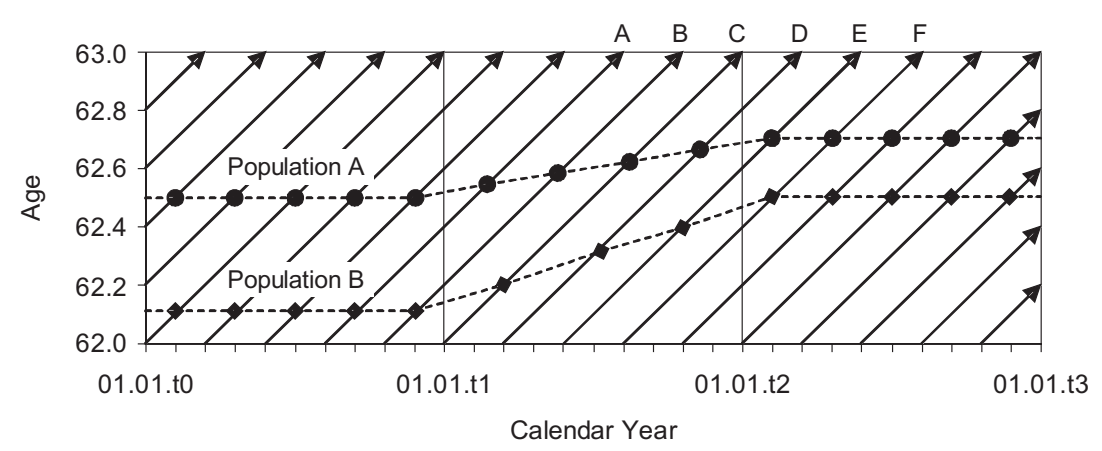

(1b) two populations with differently decreasing mortality in year t1

Fig. 1. Mortality tempo effect illustrated in the Lexis diagram.

age at death of cohorts $\mathrm{A}$ to $\mathrm{E}$ increases steadily and cohort $\mathrm{E}$ is the first to reach the new age at death level of 62.7 years. Since each of the five cohorts lives longer than the preceding one, the intervals between the deaths are longer than they are between the births (both intervals are identical before the year of changing mortality conditions t1). Consequently, the deaths to the five cohorts that reach age 62.5 during year t 1 are spread over a period exceeding one year. As a result, the deaths of persons belonging to cohort $\mathrm{E}$ are shifted to year t2, shown by the thick grey arrow in Figure 1a. Following Vaupel (in this volume p. 93), the shift can also be interpreted as "saved lives" in year $\mathrm{t} 1$. The number of deaths in year $\mathrm{t} 1$ declines by 1,000 when compared to the scenario before the mortality conditions changed. This is demonstrated in Figure 1a: Only four black dots are seen in year t1. Had mortality not changed during that year, there would have been five dots in year t1, as demonstrated by the unfilled dots representing age at death to cohorts according to the old mortality conditions until year t0. Due to the reduced number of deaths and 
the risk years gained in year $\mathrm{t} 1$, the age-specific death rate for age 62 decreases to:

$$
M_{62, t 1}^{A}=\frac{4,000}{98,400}=0.04065 .
$$

The mortality decline is reflected in the decreasing age-specific death rate. If such mortality change occurred similarly at the other ages, this would lead to an increase in life expectancy that is derived from the age-specific death rates. Figure 1a shows that the decline in the annual number of deaths is transitory in that it disappears when the age at death stops rising. From year t2 on, the intervals between births and deaths are, again, identical and there are 5,000 deaths in each subsequent calendar year, leading to the age-specific death rate:

$$
M_{62, t 2}^{A}=\frac{5,000}{98,500}=0.05076
$$

Since the number of deaths in the numerator increases relatively steeper than the number of risk years lived in the denominator, the period death rate for year $\mathrm{t} 2$ will be higher than that for year $\mathrm{t} 1$, although the average age at death is higher in $\mathrm{t} 2$ than it is in $\mathrm{t} 1$. As a consequence, life expectancy would decrease between $\mathrm{t} 1$ and $\mathrm{t} 2$. Since period life expectancy is generally seen as an indicator for period mortality conditions, such a decrease is likely to be interpreted as an increase in mortality. However, Figure 1a shows that no cohort experiences any increase in mortality. In Bongaarts and Feeney's approach, such a discrepancy between the development of mortality conditions and its representation in period death rates (or measures derived from them, such as life expectancy) represents a tempo effect. The logic behind this argument is neither limited to the simple assumptions of this example (constant number of births, birth intervals of 0.2 years) nor is it restricted to one single age group. If we increased the number of age groups and assumed that the ages at death in these groups rise at different rates, then different numbers of deaths would be shifted and the magnitude of the tempo effect would vary from one age group to another (for more details, see Feeney, 2003).

When the trend in period life expectancy is used in order to analyze the changing mortality conditions of a specific population, such tempo effects may not be a problem as long as there is no sudden change or stagnation of mortality. However, tempo effects may lead to a distorted picture when mortality conditions of two populations are compared that experience mortality changes that differ in their patterns of change. This is demonstrated by introducing an additional population $B$ to the illustration in Figure 1b. As with population A, all births in population B occur intermittently at intervals of 0.2 years, mortality remains unchanged until year t0 and at the end of year t0, the age at death begins to increase linearly and cedes increasing at the end of the year. Compared to population A, the cohorts of population B show lower ages at death at any time. Until year t0 all deaths at age 62 occur at the exact age 
of 62.1 and the change during year t1 leads to an increased age at death of 62.5 years, thus being equivalent to the mortality conditions of population A until year t0. Using the same logic of calculating the age-specific death rates for population B, it follows for the years $\mathrm{t} 0$, $\mathrm{t} 1$, and $\mathrm{t} 2$ that:

$$
\begin{aligned}
& M_{62, t 0}^{B}=\frac{5,000}{95,500}=0.05236, \\
& M_{62, t 1}^{B}=\frac{3,000}{97,900}=0.03064, \\
& M_{62, t 2}^{B}=\frac{5,000}{97,500}=0.05128 .
\end{aligned}
$$

Although no cohort of population B experiences lower mortality than the cohorts of population $\mathrm{A}$, the death rate for population $\mathrm{B}$ in year $\mathrm{t} 1$ is lower than the death rate for population $\mathrm{A}$. This is due to the fact that during year t1 mortality changes in population B are stronger than they are in population A. The higher increase of the age at death in population B leads to higher tempo distortions in $\mathrm{t} 1$ compared to population A.

Despite the confusing outcome, the examples represented in Figures 1a and $1 \mathrm{~b}$ show that there is no mistake in the calculation of period death rates. There might be research questions where the conventional period rates are interesting, e.g. to analyze and forecast the annual number of deaths. However, the examples also show that the conventional way of calculating period measures may convey the wrong message whenever demographic conditions are changing in the year or period analyzed. As to life expectancy, one can make generalizations as already described by Bongaarts and Feeney (2002): If mortality declines, then life expectancy overestimates current conditions; if mortality rises, then life expectancy underestimates current survival conditions. The bias is the more marked, the more intensive the changes are during the period observed.

All demographic period measures are hypothetical estimates to standardize for current demographic conditions. Since different populations have different experiences of changes in the mean age at death, tempo effects impact them differently, as do different age compositions of the populations. Thus, tempo effects should generally be seen and treated as a distortion of period measures, as the effects of population age composition. Bearing in mind the simple examples above, the question arises as to the meaning that period measures based on current rates have in a world of continuous demographic change. This holds especially when populations with entirely different demographic developments are compared, such as the populations of West and East Germany. To assure that conventional period measures do not point into the wrong direction, it is necessary to look at tempo-adjusted measures regardless of whether fertility, mortality, or any other demographic process is analyzed. 


\section{Why life expectancy differences between western and eastern Germany call for tempo-adjustment}

The demographic changes and developments in eastern and western Germany are generally seen to present a unique opportunity to understand the interaction between societal, social, and economic conditions on the one hand, and population processes on the other. The German experience thus is used to understand the reasons behind recent mortality changes. The two pre-war German regions were characterized by a demographic composition and behavior that was almost identical until 1945, followed however by 45 years under different political and socioeconomic structures and resulting in demographic developments that were entirely different (Dinkel, 1992, 1994, 1999; Gjonça et al., 2000). With unification in 1990, East Germany adopted the western societal and economic system, causing sudden changes in all of its demographic processes. These conditions - leading some scholars to describe the eastern German population as a kind of "natural experiment" (Dinkel, 1999; Vaupel et al., 2003) - generated a large number of studies on the changes in eastern German demography. Of central interest in the field of mortality research has been the rapid convergence of life expectancy since 1990 following roughly two decades of continuous divergence. The former widening and the subsequent closing in the life expectancy gap between western and eastern Germany were mainly caused by the age groups $60-80$, leading to the central message that "it's never too late" to increase one's length of life (Vaupel et al., 2003).

Figure 2 shows the trends in period life expectancy at birth $e_{0}$, using standard life table techniques for western and eastern German women and men for each single calendar year from 1950 to 2004. The life table calculations are based on official population statistics, i.e. data for the living population and deaths for each calendar year and single age groups (for a more detailed description of these data, see Luy, 2004a) ${ }^{6}$.

Regarding mortality differences between western and eastern Germany, the time span presented can be subdivided into five central phases:

- The first phase, from 1950 to roughly 1960, is characterized by irregular fluctuations, with several years of mortality crossing over. These trends correspond with the waves of influenza that swept East and West Germany

\footnotetext{
${ }^{6}$ Because of a reform to Berlin's district borders in the year 2000 it has been impossible since then to divide the population and the demographic events of Berlin into eastern and western Berlin according to the former borders of separated Germany. Thus, from the year 2000 onwards, the Statistical Office of Germany divides population data into western Germany without Berlin, eastern Germany without Berlin, and Berlin. In order to get a complete time series of life tables for eastern Germany (former GDR) and western Germany (former FRG) from 1950 to 2004, I divided the data on Berlin's living population and deaths of the years 2000 to 2004 into east and west according to the sex-specific share of inhabitants of eastern and western Berlin of the year 1999, assuming identical mortality for both parts of the city from the year 2000 onwards.
} 

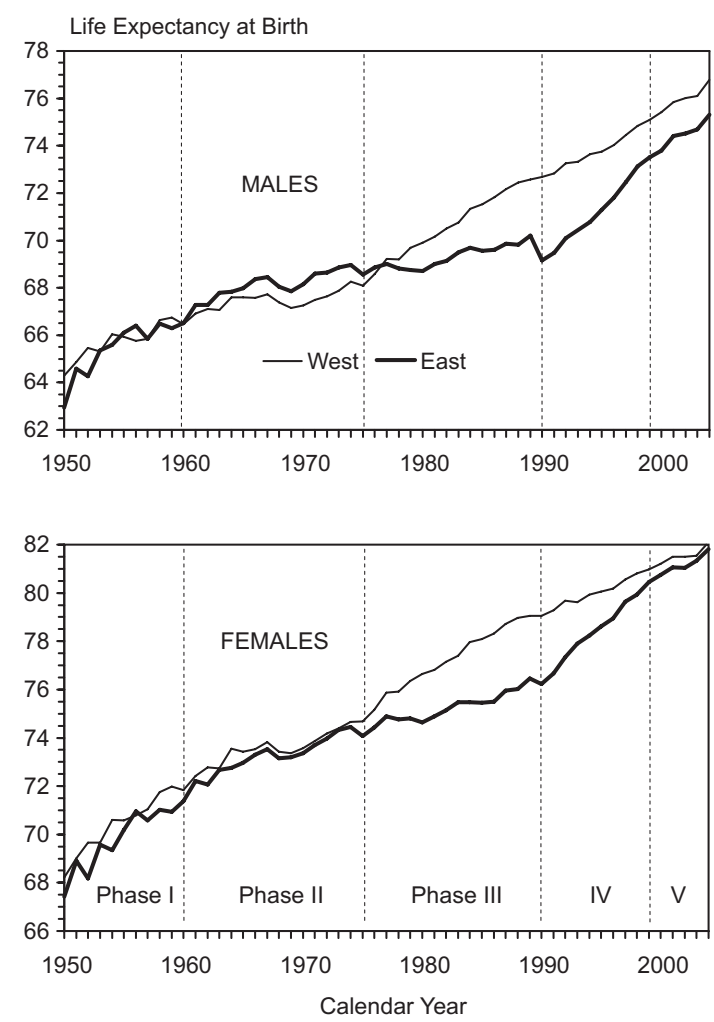

Fig. 2. Trends in conventional life expectancy at birth for western and eastern Germany, 1950-2004.

in different years (Luy, 2004a). No mortality differences can be detected between the two Germanys, neither for men nor for women.

- In the second phase, roughly covering the period 1960 to 1975 , the developments in life expectancy in West and East Germany assumed more regularity, with mortality slightly higher among East German women and significantly lower among East German men. The differences in favor of East German males rose until the first half of the 1970s and reached a maximum of roughly one year in life expectancy at birth. However, the disadvantage of West German men arose mainly from different definitions of live birth in East and West Germany, thus causing lower infant mortality rates in the former GDR on statistical ${ }^{7}$ grounds. An analysis of age-specific differences between West and East German mortality shows

\footnotetext{
${ }^{7}$ In West Germany, the result of childbirth is defined as live birth if one of three signs of life, namely heart-beat, natural respiration, or a pulsating umbilical cord, is evident. In East German statistics, live birth was defined only by heartbeat and simultaneous natural respiration (Müller, 1976). Consequently, all deaths of newborns showing only one of the three signs of life are registered as live births
} 
that the higher life expectancy among East German men mainly (but not only) resulted from statistically lower infant mortality (Luy, 2004a).

- The third phase, starting in the middle of the 1970s, is characterized by the continuous divergence for both sexes in the development of mortality conditions in favor of West Germany. This development corresponds to the general divergence in mortality trends between all western and eastern European countries (e.g. Caselli and Egidi, 1980; Bourgois-Pichat, 1985; Bobak and Marmot, 1996a, 1996b; Hertzman et al., 1996; Meslé and Hertrich, 1997; Vallin and Meslé, 2001; Meslé and Vallin, 2002). Figure 1 shows that the widening of the life expectancy gap was caused by the fact that East German life expectancy at birth increased at a lower pace for both sexes, whereas life expectancy in West Germany rose more rapidly (Höhn and Pollard, 1991; Scholz, 1996; Gjonça et al., 2000; Nolte et al. 2000a). The differences peaked in 1988 for women (almost 3 years) and in 1990 for men (roughly 3.5 years).

- These peaks - virtually concurring with German unification - were followed by the continuous narrowing of the gap in west-east German mortality differences until the end of the 1990s, when the difference in $e_{0}$ reached about 0.5 years for women and about 1.6 years for men. As can be seen in Figure 2 , as the two Germanys entered this phase the differences in life expectancy trends between them started to reverse compared to the trends in the third phase. The convergence of mortality levels now observable is due to the fact that since the beginning of the 1990s life expectancy has been rising much faster in eastern Germany than in the west. Based on these observations, German demographers assumed that the west-east mortality gap will fully close during the first two decades of the 21 st century, as reflected in one of the most recent population forecasts of the Statistical Office of Germany (Statistisches Bundesamt, 2003).

- However, around the year 2000, this trend changed again. The differences in life expectancy between eastern and western German men now stagnate on a level around 1.5 years. Eastern German women, by contrast, seem to further approximate the western German level, however with a decline in the pace of approximation and with the difference now being around 0.25 years.

Figure 2 shows a striking decrease in life expectancy among eastern German men in 1990, a phenomenon described as the eastern German "mortality crisis" (Dorbritz and Gärtner, 1995; Riphan, 1999; Nolte et al., 2000a, 2000b) and as characteristic of a "demographic shock" in connection with the changes in eastern Germany resulting from unification (Eberstadt, 1994). However, long-term trends in life expectancy question the aptness of this description and call for an explanation of the rapid closing of the gap. The decisive question is: Which factor or which factors are responsible for the trend reversal in

and thus as infant deaths only in West Germany, whereas in East Germany such cases were registered as stillbirths and did not enter mortality statistics. 
mortality differences between western and eastern Germany, a trend reversal that has occurred within one or two years only? The factors discussed most in search of an answer are the same that are assumed to be responsible for the general mortality gap between western and eastern European countries (e.g. Bobak and Marmot, 1996a, 1996b; Hertzman et al., 1996; for the discussion on the mortality differences between eastern and western Germany, see Luy, 2004a): East German working conditions, environmental conditions, the consequences of uranium mining and storage, the effects of the ongoing immigration of a more healthy foreign population to West Germany, selective internal east-west migration, psychological reactions to the political suppression, economic conditions, medical technology, lifestyles, and cardiovascular risk factors.

The similarity to the general European west-east divergence makes the search for the reasons behind the mortality trends in eastern Germany a subject of major interest that reaches beyond the borders of Germany. Additionally, it seems that finding the main cause(s) for the mortality differences between western and eastern Germany will be an important step forward in gaining a deeper understanding of general mortality differentials. A large and continuously increasing number of studies follow this path based on trends in life expectancy such as shown in Figure 2 (e.g. Chruscz, 1992; Dinkel, 1994, 1999; Schott et al., 1994; Becker and Boyle, 1997; Gjonça et al., 2000; Bucher, 2002; Nolte et al., 2002; Luy, 2004a, 2004b, 2005b; Mai, 2004). Although many researchers are working on this subject, the rapid approximation of life expectancy is still not explained in full.

However, following Bongaarts and Feeney's tempo approach, we must conclude that period life expectancy based on annual age-specific death rates is an imperfect solution for the reflection of period mortality conditions. As has been shown in the previous chapter, this is because death rates are biased downward with rising mean age at death (mortality decline) and they are biased upward when the mean age at death declines (mortality increase). Since different populations experience changes in the mean age at death with different paces, tempo effects impact them differently. Phases of mortality decline and phases of mortality increase set in in eastern and western Germany in different years and with different pace, coinciding with observed trends in life expectancy differences between the two parts of Germany: during Phase 3, life expectancy increased continuously in West Germany, whereas it rose only slightly or remained constant in the east. During Phase 4, life expectancy rose more steeply in eastern Germany than in the west. We can assume that the sudden improvements in eastern Germany after unification, for instance in economic conditions and medical technology, caused postponement of deaths in almost all age groups to an extent that was not possible in western Germany, where these conditions have already been on a high level. Similarly, for the years preceding unification we can expect that more deaths among western German women and men have been postponed as a consequence of increasing advantages in living conditions and medical standards. If these different 
trends are causing tempo distortions in the sense of Bongaarts and Feeney's approach, then the studies on the causes of eastern German excess mortality are based on data leading to a distorted picture of mortality conditions in the two German regions and thus to the differences between them. In the final consequence, this may be the reason why the factor(s) mainly responsible for the impressive improvement of mortality conditions in eastern Germany is (are) still undetected.

(a) West Germany, Males

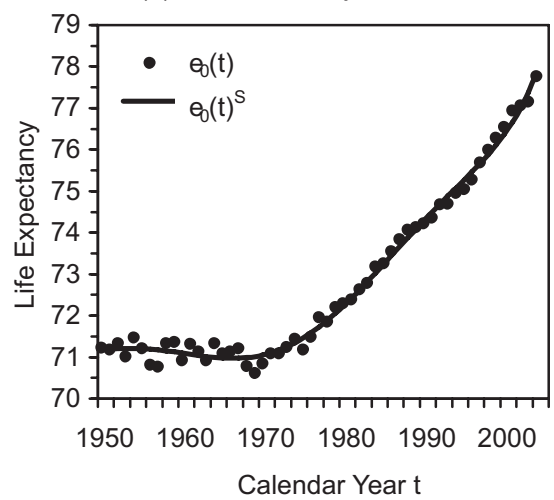

(c) West Germany, Females

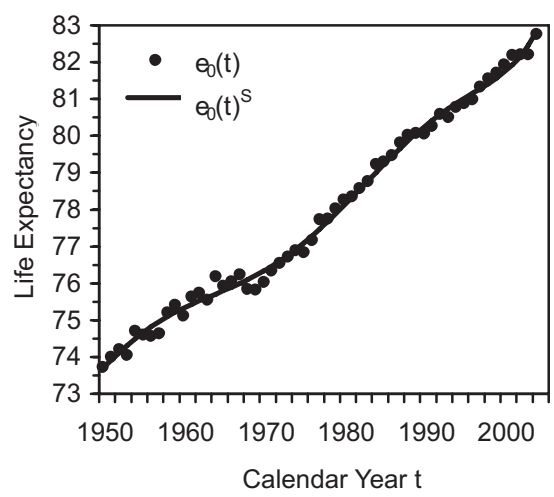

(b) East Germany, Males

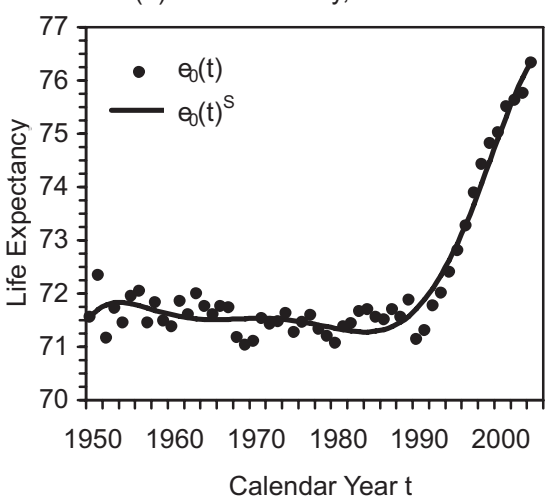

(d) East Germany, Females

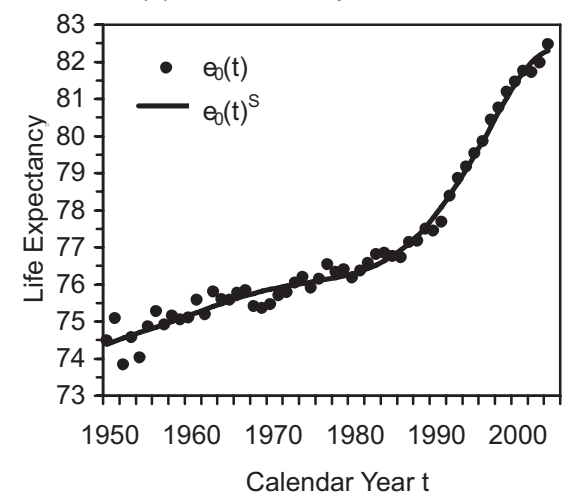

Fig. 3. Conventional life expectancy at birth $e_{0}(t)$ and smoothed estimates $e_{0}(t)^{S}$ (sixth degree polynomial), western and eastern Germany, 1950-2004 (no mortality under age 30$)$.

In the following, tempo-adjusted life expectancy, denoted by $e_{0}^{*}(t)$, for western and eastern Germany, is estimated by using the indirect technique proposed by Bongaarts and Feeney (2002) in their initial paper on tempo 
effects in mortality, assuming no mortality under age 30 . Figure 3 shows the smoothed trends in conventional life expectancy at birth with mortality below age 30 set to 0 for each of the four populations observed (i.e., $e_{0}(t)=e_{30}(t)+$ $30)$. These functions form the base for the method used to calculate tempoadjusted life expectancy $e_{0}^{*}(t)$ in eastern and western Germany. The formula used for tempo-adjusted life expectancy is

$$
e_{0}^{*}(t)=e_{0}(t)+\frac{1}{b} \ln \left(1-\frac{d e_{0}^{*}(t)}{d t}\right),
$$

with $b$ denoting the "Gompertz parameter" estimated by fitting a Gompertz model to annual age-specific death rates. The methods of estimation and the calculations done for western and eastern Germany are provided in the Appendix.

\section{Trends in tempo-adjusted life expectancy in western and eastern Germany}

Figure 4 shows the trends in conventional and tempo-adjusted life expectancy at birth (no mortality under age 30 in both cases) from 1975 to 2004 for western and eastern German females and males. The graph for western German females (Figure 4c) is very similar to the figures for US and Japanese women presented by Bongaarts and Feeney (2002: 24). As can be seen in Figure 3(c), western German females represent the only of the four populations analyzed with an observed life expectancy at birth that has been increasing almost constantly since 1950 . Thus, the tempo distortion $S(t)$ (defined as the difference between conventional and tempo-adjusted life expectancy) is relatively constant among western German females during the observation period. Since improvements in life expectancy developed later (western and eastern German males) or at a changing pace (eastern German females) among the other three populations, tempo distortions must vary when compared to western German females. This is well reflected by the results gained for $e_{0}^{*}(t)$ and $S(t)$, as can be seen in Figure 4.

In all cases, the estimated tempo distortions agree with the logic of mortality tempo effects. This becomes clear when comparing Figures 3 and 4 . The tempo distortion $S(t)$ was very low among West German men in 1975 and then increased steadily until the second half of the 1980s, when the difference between conventional and tempo-adjusted life expectancy reached an almost constant level (Figure 4a). It can be seen in Figure 3(a) that life expectancy among West German men remained more or less unchanged between 1950 and 1970, thus one cannot expect a noticeable tempo distortion in the mid 1970s. Rising life expectancy after 1970 is caused a by shift in the average age at death and thus the tempo-adjusted life expectancy also starts to increase, 
although at a lower pace than does conventional life expectancy. Among eastern German males, life expectancy remained constant or even declined slightly until the end of the 1980s and then started to rise at a higher pace than in any phase of life expectancy trends in western Germany (Figures 3a and 3b). Consequently, tempo-adjusted life expectancy $e_{0}^{*}(t)$ did not differ from conventional life expectancy until the beginning of the 1990s and then began to increase at a considerably lower rate compared to $e_{0}(t)$. The extent of tempo distortions in conventional life expectancy grew during the observed period among eastern German females, too. From Figure 3(d) we know that their life expectancy rose in the period preceding unification, although it did so at a lower pace than among their West German counterparts (see also Figure 2). As a result, tempo distortions, i.e. the difference between tempo-adjusted and conventional life expectancy, remained at an almost constant level between 1975 and 1990. However, the difference between $e_{0}(t)$ and $e_{0}^{*}(t)$ started to increase at the end of the 1980s when conventional life expectancy rose at a higher rate - a phenomenon similar to what has been observed among men in the eastern part of Germany (Figures $4 \mathrm{~b}$ and $4 \mathrm{~d}$ ).

The most important question is the way in which the differences in life expectancy between western and eastern Germany developed in the observation period 1975 to 2004 when adjusted for tempo distortions. The corresponding results are given in Figures 5 and 6 for males and females respectively; the single values can be found in Table 1 . The thinner lines in the two graphs represent the absolute difference between western and eastern Germany in conventional life expectancy and the bold lines show the difference in tempo-adjusted life expectancy. Figure 5 again depicts the rapid decrease in conventional life expectancy differences after 1990, following a continuous increase since the beginning of the observation period. Whereas West German males enjoyed a higher life expectancy according to conventional calculation methods since 1976, East German men showed a higher tempo-adjusted life expectancy until 1981. Note that the different definitions of live birth do not affect the results presented in this section; thus there seems to be a real East German mortality advantage among men in the 1970s. Only after 1981 did the differences in tempo-adjusted life expectancy switch to an advantage for West German males, although much less so than the results based on conventional life expectancy. The graph demonstrates that the trend in increasing west-east differences occurred at a lower pace once life expectancy is adjusted for tempo effects. In 1990, when the difference in conventional life expectancy between West and East German men reached a peak of 3.08 years, the difference in tempo-adjusted life expectancy was only 1.07 years, i.e. two years less. The finding that the latter differences did not decrease since unification but continued to increase until the end of the 1990s is even more interesting. While the difference in conventional life expectancy between western and eastern German males declined to roughly one and a half years in 2004, those in tempo-adjusted life expectancy are now even higher, with a difference of about 1.6 years. Only at the end of the 1990s did the trend in increasing 
(a) western Germany, Males

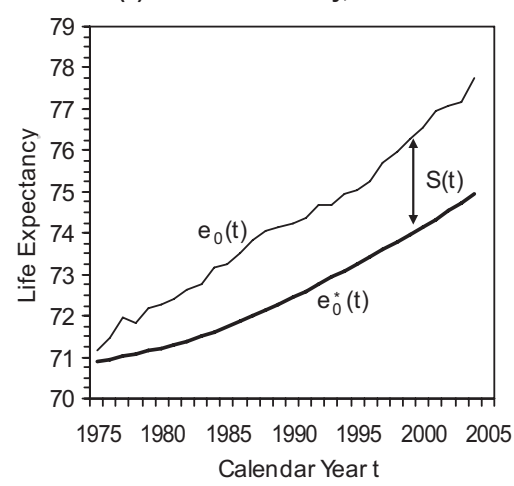

(c) western Germany, Females

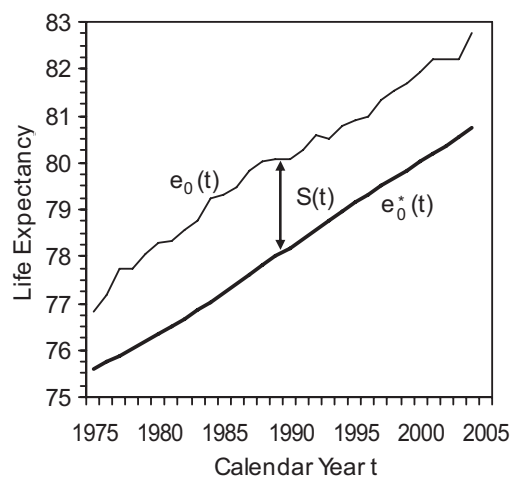

(b) eastern Germany, Males

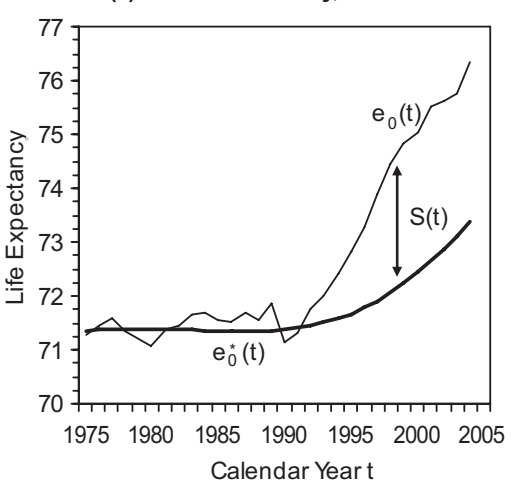

(d) eastern Germany, Females

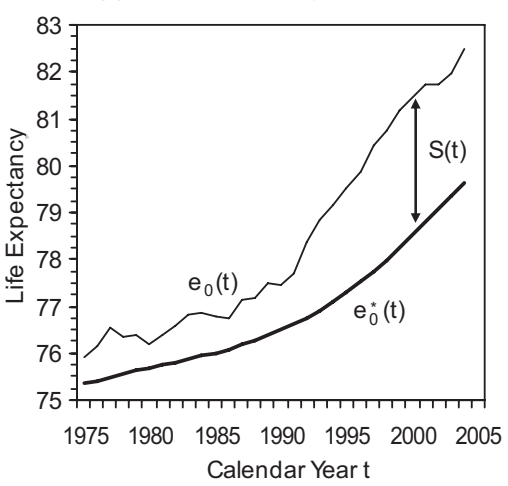

Fig. 4. Conventional life expectancy at birth $e_{0}(t)$ and estimated tempo-adjusted life expectancy at birth $e_{0}^{*}(t)$ with tempo distortion $S(t)$, western and eastern Germany, 1975-2004 (no mortality under age 30).

differences in tempo-adjusted life expectancy lower in speed, pointing to slow convergence solely in the last years of the observation period.

The results for the west-east German differences among females are similar to those just described for males. Until unification, the advantage in mortality conditions of West German females is lower when tempo-adjusted life expectancy is used instead of conventional life expectancy. Whereas the difference in conventional life expectancy increased to 2.85 years in 1988 , those in tempo-adjusted life expectancy did never exceed 1.9 years. Similar to the situation among men, the differences in tempo-adjusted life expectancy between western and eastern German females did not decline with unifica- 


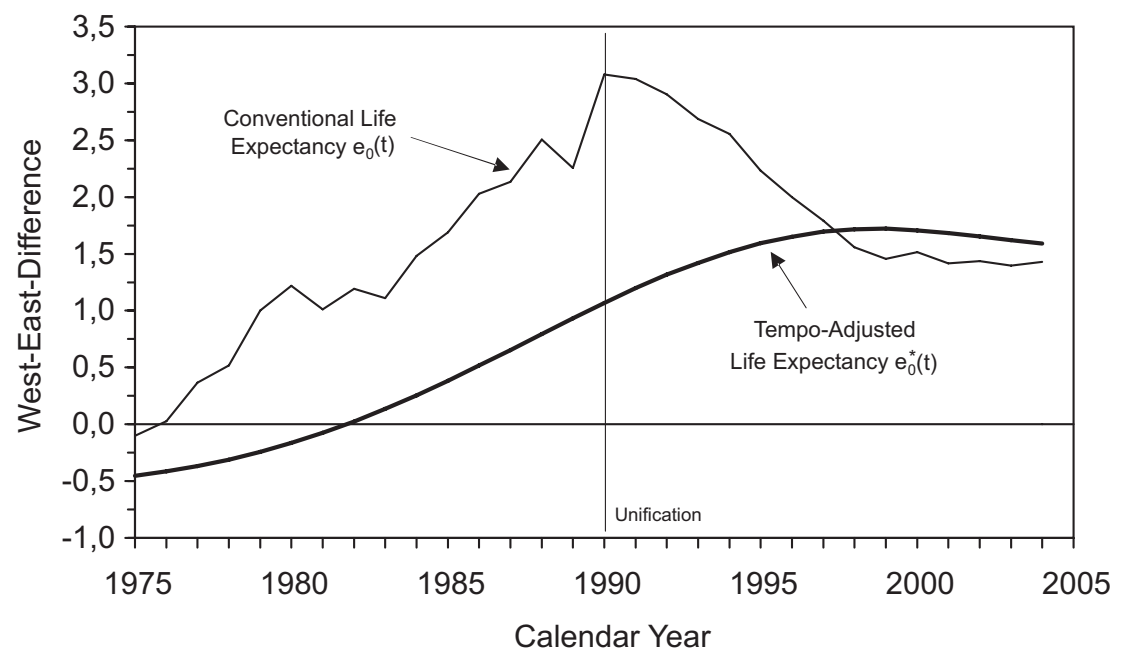

Fig. 5. West-east German difference in life expectancy at birth for conventional life expectancy $e_{0}(t)$ and tempo-adjusted life expectancy $e_{0}^{*}(t)$, males 1975-2004 (no mortality under age 30).

tion parallel to conventional life expectancy but instead rose until the mid 1990s. The trends in conventional and tempo-adjusted life expectancy crossed over between 1992 and 1993. From then on, the mortality advantage of western German females measured with tempo-adjusted life expectancy is higher when compared to the results based on tempo-unadjusted values. Although a decreasing trend in mortality differences between western and eastern German females is also evident with tempo-adjusted life expectancy since the mid 1990s, the remaining differences in favor of western German women are still considerably higher. While the disadvantage of eastern German women decreased to 0.28 years in the year 2004 according to conventional life expectancy, the tempo-adjusted difference still shows 1.1 years.

\section{Discussion}

The idea of mortality tempo effects is derived directly from the idea of fertility tempo effects; the latter have been known since more than half a century and they experience growing acceptance. Following similar approaches of Ryder (1956, 1964) or Ward and Butz (1980), Bongaarts and Feeney (1998) proposed a new method to estimate the tempo bias in period fertility rates and they provided a formula to adjust the TFR for these distortions. A few years later, Bongaarts and Feeney (2002) extended this approach to the analysis 


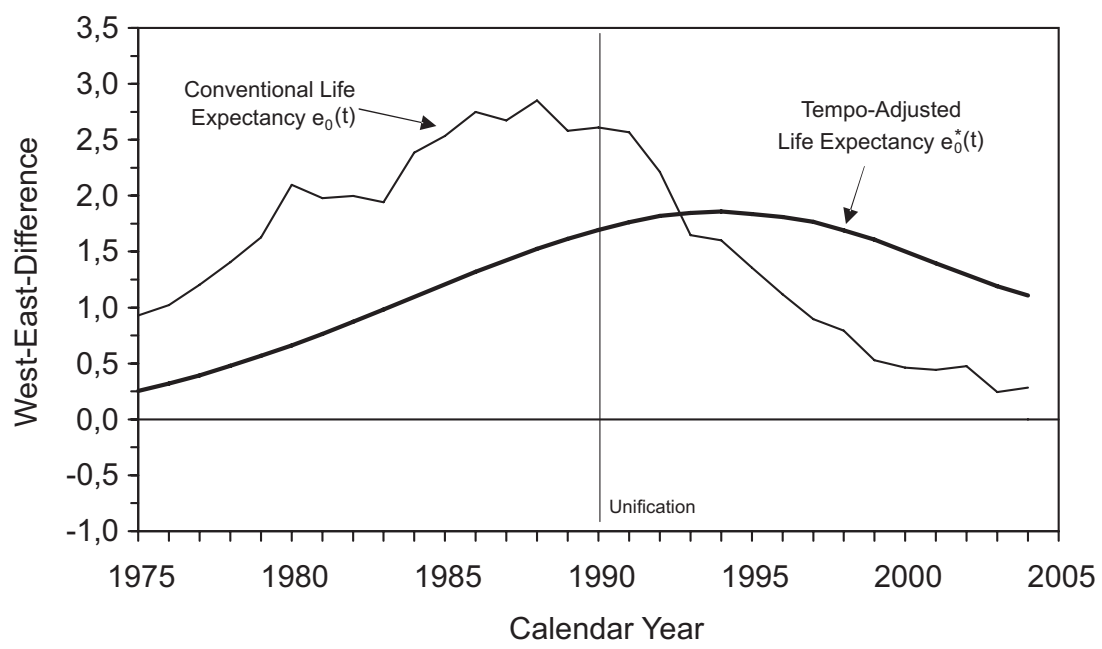

Fig. 6. West-east German difference in life expectancy at birth for conventional life expectancy $e_{0}(t)$ and tempo-adjusted life expectancy $e_{0}^{*}(t)$, females 1975-2004 (no mortality under age 30 ).

of mortality and claimed that tempo effects bias period life expectancy, too. In contrast to the situation in the field of fertility, the tempo approach in mortality generally still is rejected. However, if we accept the need for tempoadjustment in the period TFR, we equally have to accept the need for this adjustment in period life expectancy. The basic idea of the TFR is to estimate the fertility quantum under current fertility conditions as a standardized indicator for current fertility conditions. Changes in the mean age at childbirth cause tempo effects which, in turn, affect age-specific fertility rates and thus the TFR that is based on them. The same holds for period life expectancy. The basic idea of life expectancy is to estimate the average length of life under current mortality conditions as a standardized indicator for current mortality conditions. Changes in the mean age at death are causing tempo effects, which affect age-specific death rates and thus life expectancy that is based on them.

There seems to be a misunderstanding in that Bongaarts and Feeney are assumed to have intended to estimate period measures with a certain cohort meaning. This is, however, not exactly so. As to their basic application of their method, they instead used cohort experiences in order to estimate current changes in age-specific mortality conditions. Thus, Bongaarts and Feeney's tempo approach has to be distinguished from methods in order to translate 
Table 1. West-east German difference in life expectancy at birth according to conventional life expectancy $e_{0}(t)$ and tempo-adjusted life expectancy $e_{0}^{*}(t), 1975-2004$ (no mortality under age 30 ).

\begin{tabular}{|c|c|c|c|c|c|c|c|c|c|}
\hline \multicolumn{5}{|c|}{ Years before unification } & \multicolumn{5}{|c|}{ Years after unification } \\
\hline \multirow[b]{2}{*}{ Year } & \multicolumn{2}{|c|}{ Males } & \multicolumn{2}{|c|}{ Females } & \multirow[b]{2}{*}{ Year } & \multicolumn{2}{|c|}{ Males } & \multicolumn{2}{|c|}{ Females } \\
\hline & $e_{0}(t)$ & $e_{0}^{*}(t)$ & $e_{0}(t)$ & $e_{0}^{*}(t)$ & & $e_{0}(t)$ & $e_{0}^{*}(t)$ & $e_{0}(t)$ & $e_{0}^{*}(t)$ \\
\hline 1975 & -0.10 & -0.45 & 0.93 & 0.25 & 1990 & 3.08 & 1.07 & 2.61 & 1.69 \\
\hline 1976 & 0.03 & -0.42 & 1.02 & 0.32 & 1991 & 3.04 & 1.20 & 2.57 & 1.76 \\
\hline 1977 & 0.37 & -0.37 & 1.20 & 0.39 & 1992 & 2.90 & 1.32 & 2.21 & 1.82 \\
\hline 1978 & 0.52 & -0.31 & 1.41 & 0.48 & 1993 & 2.69 & 1.42 & 1.65 & 1.85 \\
\hline 1979 & 1.00 & -0.24 & 1.63 & 0.57 & 1994 & 2.55 & 1.51 & 1.60 & 1.86 \\
\hline 1980 & 1.22 & -0.17 & 2.10 & 0.66 & 1995 & 2.23 & 1.60 & 1.36 & 1.84 \\
\hline 1981 & 1.01 & -0.08 & 1.98 & 0.76 & 1996 & 2.00 & 1.65 & 1.12 & 1.81 \\
\hline 1982 & 1.19 & 0.02 & 2.00 & 0.87 & 1997 & 1.79 & 1.69 & 0.90 & 1.76 \\
\hline 1983 & 1.11 & 0.14 & 1.94 & 0.98 & 1998 & 1.56 & 1.72 & 0.79 & 1.69 \\
\hline 1984 & 1.48 & 0.25 & 2.38 & 1.10 & 1999 & 1.46 & 1.72 & 0.53 & 1.61 \\
\hline 1985 & 1.69 & 0.38 & 2.53 & 1.21 & 2000 & 1.52 & 1.71 & 0.46 & 1.50 \\
\hline 1986 & 2.03 & 0.52 & 2.75 & 1.32 & 2001 & 1.42 & 1.68 & 0.44 & 1.39 \\
\hline 1987 & 2.13 & 0.65 & 2.67 & 1.42 & 2002 & 1.44 & 1.65 & 0.48 & 1.29 \\
\hline 1988 & 2.51 & 0.79 & 2.85 & 1.52 & 2003 & 1.40 & 1.62 & 0.24 & 1.19 \\
\hline 1989 & 2.25 & 0.93 & 2.58 & 1.61 & 2004 & 1.43 & 1.59 & 0.28 & 1.11 \\
\hline
\end{tabular}

period information into cohort information ${ }^{8}$. The misunderstanding possibly originates from several sources. The first may be the title of their original paper "How long do we live?" since the term "we" does only make sense in the cohort perspective and does not exist in the logic of pure period measures. Another reason may be the similarity of Bongaarts and Feeney's tempo-adjusted life expectancy to other period measures that have clearly defined cohort components, such as the "cross-sectional average length of life" (CAL) introduced by Brouard (1986) and Guillot (2003a) or the "mean length of life" proposed by Sardon $(1993,1994)$.

In principal, the Bongaarts and Feeney adjustment formulae for the TFR and for life expectancy follow the same basic idea in that they assume that period effects influence all currently living cohorts identically. In the case of fertility, the tempo-adjustment formula is based on a shift of the age-specific fertility schedule; in the case of mortality, the original tempo-adjustment formula is based on a shift of the age-specific mortality schedule. However, since the TFR and life expectancy are fundamentally different in their structural

\footnotetext{
${ }^{8}$ Goldstein (in this volume) showed that in conditions of steady mortality change, tempo-adjusted life expectancy with the Bongaarts and Feeney formula can indeed be used as a measure of cohort life expectancy. However, since the formula contains no direct cohort component - as is shown in the Appendix of this chapter - the primary interpretation should be made in a period context.
} 
designs, the adjustment formulae must include fundamental differences. The tempo-adjusted TFR depends only on age-specific fertility rates within a small neighborhood of the analyzed calendar year. This does not hold for the Bongaarts and Feeney formula for the tempo-adjusted life expectancy used in this chapter. The major difference to the fertility procedure is that the proposed adjustment method for life expectancy uses a series of previous period life tables. Consequently, it is evident that the Bongaarts and Feeney formula reflects past mortality conditions in a certain way. But in the logic of tempo distortions, this does not necessarily represent an inconsistency, especially when past changes in mortality conditions are steady and continuous, which approximately holds for adult ages in developed populations and in the last decades. Since these are the restrictions that Bongaarts and Feeney (2002) have made to the applicability of their tempo-adjustment formula for life expectancy, we should not see it as problematic that it leads to values close (but not exactly) to a weighted moving average of past period life expectancy, as Wachter (in this volume) has shown. Just the contrary, in restricting the application to the industrialized countries of the recent past, this property of the Bongaarts and Feeney formula is consistent with the theoretical idea of tempo distortions in life expectancy.

However, we cannot see the Bongaarts and Feeney formula providing a perfect measure for tempo-adjusted period mortality conditions. As already shown by several scholars, their formula is based on assumptions which cannot be met in full by reality (e.g. Goldstein, in this volume). Thus, we should see the Bongaarts and Feeney formula as an attempt to standardize for tempo effects in period life expectancy to obtain a better measure for comparing period mortality conditions. It is, however, not clear to which extent the Bongaarts and Feeney method catches factual tempo effects and it is not possible to assess whether it presents a maximum distortion in the sense that the truth lies somewhere between conventional and tempo-adjusted life expectancy, as discussed by Vaupel (in this volume p. 93). While the constant shape assumption turned out to be robust against moderate deviations (Feeney, in this volume), several scholars described specific characteristics of the Bongaarts and Feeney formula that under certain conditions may be partly inconsistent with the general idea of tempo-adjustment (e.g. Wachter, in this volume; Wilmoth, 2005; Guillot, in this volume). Nevertheless, it is important to separate these methodological aspects from the question of the general existence of tempo effects in period life expectancy in order to do justice to Bongaarts and Feeney's tempo approach.

The empirical results presented in this chapter are striking and may be important for the general understanding of several phenomena connected with changing mortality: once life expectancy is adjusted for tempo effects, the differences between western and eastern Germany do not decrease immediately after unification and ten years later they still are higher when compared to the differences in conventional life expectancy. Taking into consideration what we know about mortality trends and their driving factors, the following question 
arises: Which of the two stories describes better what we can expect the mortality differences between western and eastern Germany to look like? We know that mortality differences such as these are caused by a number of different factors that cannot be separated empirically and that may work in opposite directions. This group of factors certainly includes some long-term effects on the mortality conditions of a population, such as the health consequences of environmental conditions or uranium mining and storage, or other long-term effects that are still working against life expectancy improvements in eastern Germany, such as of the continuing immigration of a more healthy foreign population to western Germany or selective internal east-west migration. But also the factors that are able to cause sudden changes in mortality conditions will possibly take at least a few years to display their maximum effects. For instance, qualitative improvements in medical technology cannot be reached within the short span of a year, and even if eastern German's lifestyles changed immediately after 1990, the impact on health and mortality possibly develops slowly and steadily. Consequently, following more than two decades of continuous divergence, it seems unlikely that mortality improvements in eastern Germany could reach beyond the improvements made in West Germany in the first year after unification. From this point of view, the picture drawn by tempo-adjusted life expectancy fits better than that painted by conventional life expectancy the expected trends and to the fact that the disadvantages in self-reported health - known to be a good predictor of mortality conditions - of eastern German women and men decreased only slightly during the 1990s (see Luy, 2004a, 2005b). Thus, tempo-adjusted life expectancy seems to be a more realistic indicator of the level and changes in current mortality conditions than conventional life expectancy.

These aspects indicate that the discussion on the reasons for the trends in mortality differences between western and eastern Germany of the last years might have been based on inappropriate measures and thus possibly have pointed into the wrong direction. It is puzzling that no factor was found that could explain the observed trends in conventional life expectancy at birth, despite the fact that several scholars have been conducting research on the subject. However, according to the trends in west-east German differences in tempo-adjusted life expectancy, the explanatory factors obviously do not necessarily narrow the gap in life expectancy by more than two and a half years among females and by more than 1.5 years among males within ten calendar years, and they do not necessarily change trends in mortality differences immediately after unification from one year to the next year. Research should rather focus on finding the factors responsible for producing immediate and continuous postponement of deaths that are causing these tempo distortions in life expectancy but do not necessarily increase the average length of life to the extent indicated by conventional life expectancy. Besides the standard of medical technology and economic conditions, one of these factors may be the availability of nursing care that shows a similar development in differences between western and eastern Germany as does conventional life expectancy in 
the first years after unification (see Luy, 2004a, 2005b). Obviously, a comparable tempo-distorted picture is drawn by conventional life expectancy in the phase of rising differences prior to unification under changed conditions, with higher tempo distortions in period life expectancy among the West German population.

To sum up, the results of the empirical application of mortality tempoadjustment presented in this chapter indicate that the extent and the trend of the differences in mortality conditions between western and eastern Germany are not what we thought they were. It is not surprising, then, that none of the explanatory variables usually stated to explain the west-east German mortality gap fit the observed mortality trends when measured by conventional life expectancy at birth. To come back to the central statement made by Vaupel et al. (2003) on the closing west-east mortality gap in Germany: it may never be too late to increase one's length of life, but changing mortality conditions seems to take longer than trends in conventional life expectancy suggest, and the reasons for such changes may be of different kind than generally expected.

Moreover, since life expectancy without adjustment for tempo effects is one of the demographic tools most used in order to analyze mortality, we may have to reconsider our knowledge on the basis of this measure in several other aspects:

- What about the opening and the recent closing of the mortality gap between women and men in the developed world?

- What about the linear increase in record life expectancy at birth, described by Oeppen and Vaupel (2002), especially regarding the impressive slope of this increase?

- What about the increasing mortality gap between eastern and western Europe?

This chapter has shown that tempo-adjustment of life expectancy might provide a different picture of current mortality conditions than does conventional life expectancy. We can expect that tempo effects distort the analysis in all cases where the compared populations experienced different trends in changing mortality. Consequently, we should not doubt the existence of tempo effects in period life expectancy and the distortions they possibly cause. As discussed above, it is the method proposed by Bongaarts and Feeney (2002) that has to be improved since it is based on a number of assumptions that will never be satisfied in full. Having accepted the existence of tempo effects, however, this method should be preferred to using tempo-unadjusted estimates for period life expectancy as long as there are no better solutions. Thus, the main goal of the future work of formal demographers should be the development of methods for tempo-adjusted life expectancy based on less restrictive assumptions that can be applied to all contemporary and past populations, as claimed similarly by Vaupel (in this volume p. 93) and Feeney (in this volume). 


\section{References}

Becker, N. and Boyle, P. (1997). Decline in mortality from testicular cancer in West Germany after reunification. The Lancet, 350:744.

Bobak, M. and Marmot, M. (1996a). East-west mortality divide and its potential explanations: proposed research agenda. British Medical Journal, 312:421-425.

Bobak, M. and Marmot, M. (1996b). East-west health divide and potential explanations. In Hertzman, C., Kelly, S., and Bobak, M., editors, Eastwest life expectancy gap in Europe. Environmental and non-environmental determinants, pages 17-44. Dordrecht et al.: Kluwer.

Bongaarts, J. Five period measures of longevity. In this volume, also published in Demographic Research, 13:547-558. 2005.

Bongaarts, J. and Feeney, G. Estimating mean lifetime. In this volume, also published in Proceedings of the National Academy of Science, 100:1312713133. 2003.

Bongaarts, J. and Feeney, G. The quantum and tempo of life-cycle events. In this volume, also published in Vienna Yearbook of Population Research, pages 115-152. 2006.

Bongaarts, J. and Feeney, G. (1998). On the quantum and tempo of fertility. Population and Development Review, 24:271-291.

Bongaarts, J. and Feeney, G. (2002). How long do we live? Population and Development Review, 28:13-29.

Bourgeois-Pichat, J. (1985). Recent changes in mortality in industrialized countries. In Vallin, J., Lopez, A. D., and Behm, H., editors, Health policy, social policy and mortality prospects, pages 507-539. Liege: Ordina Editions.

Brouard, N. (1982). Structure et dynamique des populations. La pyramide des années vivre, aspects nationaux et examples régionaux. Espaces, Populations, Sociétés, 2:157-168.

Bucher, H. (2002). Die Sterblichkeit in den Regionen der Bundesrepublik Deutschland und deren Ost-West-Lücke seit der Einigung. In Cromm, J. and Scholz, R. D., editors, Regionale Sterblichkeit in Deutschland, pages 33-38. Augsburg and Göttingen: WiSoMed, Cromm.

Caselli, G. and Egidi, V. (1980). New trends in European mortality. Strasbourg, Council of Europe.

Chruscz, D. (1992). Zur Entwicklung der Sterblichkeit im geeinten Deutschland: die kurze Dauer des Ost-West-Gefälles. Informationen zur Raumentwicklung, 9-10:691-700.

Dinkel, R. H. (1992). Kohortensterbetafeln für die Geburtsjahrgänge 1900 bis 1962 in den beiden Teilen Deutschlands. Zeitschrift für Bevölkerungswissenschaft, 18:95-116.

Dinkel, R. H. (1994). Die Sterblichkeitsentwicklung der Geburtsjahrgänge in den beiden deutschen Staaten. Ergebnisse und mögliche Erklärungshypothesen. In Imhof, A. E. and Weinknecht, R., editors, Erfüllt 
leben - in Gelassenheit sterben: Geschichte und Gegenwart, pages 155-170. Berlin: Duncker \& Humblot.

Dinkel, R. H. (1999). East and West German mortality before and after reunification. Unpublished manuscript. University of Rostock.

Dorbritz, J. and Gärtner, K. (1995). Bericht 1995 über die demographische Lage in Deutschland. Zeitschrift für Bevölkerungswissenschaft, 20:339-448.

Eberstadt, N. (1994). Demographic shocks after Communism: Eastern Germany, 1989-93. Population and Development Review, 20:137-152.

Feeney, G. Increments to life and mortality tempo. In this volume, also published in Demographic Research, 14:27-46. 2006.

Feeney, G. (2003). Mortality tempo: a guide for the sceptic. To be downloaded from http://www.gfeeney.com.

Gjonça, A., Brockmann, H., and Maier, H. (2000). Old-age mortality in Germany prior to and after Reunification. Demographic Research, 3(1).

Goldstein, J. R. Found in translation? A cohort perspective on tempo-adjusted life expectancy. In this volume, also published in Demographic Research, 14:71-84. 2006.

Goldstein, J. R., Lutz, W., and Scherbov, S. (2003). Long-term population decline in Europe: the relative importance of tempo effects and generational length. Population and Development Review, 29:699-707.

Guillot, M. Tempo effects in mortality: an appraisal. In this volume, also published in Demographic Research, 14:1-26. 2006.

Guillot, M. (2003a). The cross-sectional average length of life $(C A L)$ : a crosssectional mortality measure that reflects the experience of cohorts. Population Studies, 57:41-54.

Guillot, M. (2003b). Does period life expectancy overestimate current survival? An analysis of tempo effects in mortality. Minneapolis, Minnesota, USA. Paper presented at the annual meeting of the PAA.

Hertzman, C., Kelly, S., and Bobak, M., editors (1996). East-west life expectancy gap in Europe. Environmental and non-environmental determinants. Dordrecht et al.: Kluwer.

Höhn, C. and Pollard, J. (1991). Mortality in the two Germanies in 1986 and trends 1976-1986. European Journal of Population, 7:1-28.

Horiuchi, S. Tempo effect on age-specific death rates. In this volume, also published in Demographic Research, 13:189-200. 2005.

Keilman, N. (2006). Demographic translation: from period to cohort perspective and back. In Caselli, G., Vallin, J., and Wunsch, G., editors, Demography: analysis and synthesis, pages 215-225. Amsterdam et al.: Elsevier.

Kim, Y. J. and Schoen, R. (2000). On the quantum and tempo of fertility: limits to the Bongaarts-Feeney adjustment. Population and Development Review, 26:554-559.

Kohler, H.-P. and Philipov, D. (2001). Variance effects in the BongaartsFeeney formula. Demography, 38:1-16. 
Le Bras, H. Mortality tempo versus removing of deaths: opposite views leading to different estimations of life expectancy. In this volume, also published in Demographic Research, 13:615-640. 2005.

Lesthaeghe, R. and Willems, P. (1999). Is low fertility a temporary phenomenon in the European Union? Population and Development Review, 25:211-228.

Luy, M. (2004a). Mortality differences between Western and Eastern Germany before and after Reunification: a macro and micro level analysis of developments and responsible factors. Genus, 60:99-141.

Luy, M. (2004b). Verschiedene Aspekte der Sterblichkeitsentwicklung in Deutschland von 1950 bis 2000. Zeitschrift für Bevölkerungswissenschaft, $29: 3-62$

Luy, M. (2005a). The importance of mortality tempo-adjustment: theoretical and empirical considerations. MPIDR Working Paper wp-2005-035. To be downloaded from http://www. demogr.mpg.de/papers/working/wp-2005035.pdf.

Luy, M. (2005b). West-Ost-Unterschiede in der Sterblichkeit unter besonderer Berücksichtigung des Einflusses von Lebensstil und Lebensqualität. In Gärtner, K., Grünheid, E., and Luy, M., editors, Lebensstile, Lebensphasen, Lebensqualität - Interdisziplinäre Analysen von Gesundheit und Sterblichkeit aus dem Lebenserwartungssurvey des BiB, pages 333-364. Wiesbaden: VSVerlag für Sozialwissenschaften.

Mai, R. (2004). Regionale Sterblichkeitsunterschiede in Ostdeutschland. Struktur, Entwicklung und die Ost-West-Lücke seit der Wiedervereinigung. In Scholz, R. and Flöthmann, J., editors, Lebenserwartung und Mortalität, Materialien zur Bevölkerungswissenschaft, volume 111, pages 51-68. Wiesbaden: BiB.

Meslé, F. and Hertrich, V. (1997). Mortality trends in Europe: the widening gap between east and west. In 23rd International Population Conference, Beijing 1997, pages 479-508. Liège: IUSSP.

Meslé, F. and Vallin, J. (2002). Mortality in Europe: the divergence between east and west. Population-E, 57:157-198.

Müller, C. K. E. (1976). Die Säuglingssterblichkeit in der Bundesrepublik Deutschland und in der Deutschen Demokratischen Republik. Bonn: Schwarzbold.

Nolte, E., Scholz, R., Shkolnikov, V., and McKee, M. (2002). The contribution of medical care to changing life expectancy in Germany and Poland. Social Science \& Medicine, 55:1905-1921.

Nolte, E., Shkolnikov, V., and McKee, M. (2000a). Changing mortality patterns in East and West Germany and Poland: I. Long-term trends. Journal of Epidemiology and Community Health, 54:890-899.

Nolte, E., Shkolnikov, V., and McKee, M. (2000b). Changing mortality patterns in East and West Germany and Poland: II. Short-term trends during transition and in the 1990s. Journal of Epidemiology and Community Health, 54:899-906. 
Oeppen, J. and Vaupel, J. W. (2002). Broken limits to life expectancy. Science, 296:1029-1031.

Philipov, D. and Kohler, H.-P. (2001). Tempo effects in the fertility decline in Eastern Europe: evidence from Bulgaria, the Czech Republic, Hungary, Poland and Russia. European Journal of Population, 17:37-60.

Riphahn, R. T. (1999). Die Mortalitätskrise in Ostdeutschland und ihre Reflektion in der Todesursachenstatistik. Zeitschrift für Bevölkerungswissenschaft, 24:329-363.

Rodríguez, G. Demographic translation and tempo effects: an accelerated failure time perspective. In this volume, also published in Demographic Research, 14:85-110. 2006.

Ryder, N. B. (1956). Problems of trend determination during a transition in fertility. Milbank Memorial Fund Quarterly, 34:5-21.

Ryder, N. B. (1964). The process of demographic translation. Demography, $1: 74-82$

Sardon, J.-P. (1993). Un indicateur conjoncturel de mortalité: l'exemple de la France. Population (French Edition), 48:347-368.

Sardon, J.-P. (1994). A period measure of mortality: the example of France. Population: An English Selection, 6:131-150.

Schoen, R. (2004). Timing effects and the interpretation of period fertility. Demography, 41:801-819.

Scholz, R. D. (1996). Analyse und Prognose der Mortalitätsentwicklung in den alten und neuen Bundesländern - Ergebnisse des Ost/West-Vergleiches der Kohortensterblichkeit. In Dinkel, R. H., Höhn, C., and Scholz, R. D., editors, Sterblichkeitsentwicklung - unter besonderer Berücksichtigung des Kohortenansatzes, pages 89-102. München: Boldt.

Schott, J., Wiesner, G., Casper, W., and Bergmann, K. E. (1994). Entwicklung der Mortalität des alten Menschen in Ost- und Westdeutschland in den zurückliegenden Jahrzehnten. In Imhof, A. E. and Weinknecht, R., editors, Erfüllt leben - in Gelassenheit sterben: Geschichte und Gegenwart, pages 171-182. Berlin: Duncker \& Humblot.

Smallwood, S. (2002). The effects of changes in timing of childbearing on measuring fertility in England and Wales. Population Trends, 109:36-45.

Sobotka, T. (2003). Tempo-quantum and period-cohort interplay in fertility changes in Europe. Evidence from the Czech Republic, Italy, the Netherlands and Sweden. Demographic Research, 8:152-214.

Sobotka, T. (2004a). Is lowest-low fertility in Europe explained by the postponement of childbearing? Population and Development Review, 30:195220.

Sobotka, T. (2004b). Postponement of childbearing and low fertility in Europe. Amsterdam: Dutch University Press.

Statistisches Bundesamt (2003). Bevölkerung Deutschlands bis 2050. 10. koordinierte Bevölkerungsvorausberechnung. Wiesbaden: Statistisches Bundesamt. 
Vallin, J. and Meslé, F. (2001). Trends in mortality in Europe since 1950: age-, sex- and cause-specific mortality. In Trends in mortality and differential mortality, pages 31-186. Strasbourg: Council of Europe Publishing. (Population Studies No. 36).

Van Imhoff, E. (2001). On the impossibility of inferring cohort fertility measures from period fertility measures. Demographic Research, 5:23-64.

Van Imhoff, E. and Keilman, N. (2000). On the quantum and tempo of fertility: comment. Population and Development Review, 26:549-553.

Vaupel, J. W. Lifesaving, lifetimes and lifetables. In this volume, also published in Demographic Research, 13:597-614. 2005.

Vaupel, J. W. (2002). Life expectancy at current rates vs. current conditions: a reflexion stimulated by Bongaarts and Feeney's 'How Long Do We Live?'. Demographic Research, 7:365-377.

Vaupel, J. W., Carey, J. R., and Christensen, K. (2003). It's never too late. Science, 301:1679-1681.

Wachter, K. Tempo and its tribulations. In this volume, also published in Demographic Research, 13:201-222. 2005.

Ward, M. P. and Butz, W. P. (1980). Completed fertility and its timing. Journal of Political Economy, 88:915-940.

Wilmoth, J. R. (2005). On the relationship between period and cohort mortality. Demographic Research, 13:231-280.

Winkler-Dworak, M. and Engelhardt, H. (2004). On the quantum and tempo of first marriages in Austria, Germany, and Switzerland: Changes in mean age and variance. Demographic Research, 10:231-263.

Zeng, Y. and Land, K. C. (2001). A sensitivity analysis of the BongaartsFeeney method for adjusting bias in observed period total fertility rates. Demography, 38:17-28.

Zeng, Y. and Land, K. C. (2002). Adjusting period tempo changes with an extension of Ryder's basic translation equation. Demography, 39:269-285. 


\section{Appendix}

In order to estimate tempo-adjusted life expectancy for western and eastern Germany, I followed the approach of Bongaarts and Feeney (2002), who defined the tempo effect $S(t)$ in life expectancy in a year $t$ as the absolute difference between the conventional life expectancy at birth $e_{0}(t)$ and the tempo-adjusted life expectancy at birth $e_{0}^{*}(t)$ (which Bongaarts and Feeney called the "average age at death"), thus

$$
S(t)=e_{0}(t)-e_{0}^{*}(t)
$$

Measure $e_{0}^{*}(t)$ is defined as the average age at death in a population with a constant number of births. This measure is closely related to the "crosssectional average length of life" (CAL) but it is not identical (see Guillot 2003b). In subsequent studies, Bongaarts and Feeney (in this volume p. 11 and p. 29) presented further possibilities to estimate in a similar manner tempoadjusted period life expectancy from complete cohort data on births, deaths, and migration respective cohort life tables in order to reconstruct empirically a constant birth population for a certain period. Detailed data such as these do not exist on the West and East German populations, however. When such cohort data is not available (at least for a time span long enough), $e_{0}^{*}(t)$ can be estimated by solving the equation

$$
e_{0}(t)=e_{0}^{*}(t)-\frac{1}{b} \ln \left(1-\frac{d e_{0}^{*}(t)}{d t}\right)
$$

for $e_{0}^{*}(t)$ from conventional life table estimates, based on the assumptions that mortality under age 30 can be neglected and that the annual changes in the force of mortality follow a shifting Gompertz function ${ }^{9}$. For a detailed derivation of this formula, see Bongaarts and Feeney (2002). As proposed by Bongaarts and Feeney (2002), value $b$ is estimated by fitting a Gompertz model to annual age-specific death rates for ages $30-90^{10}$. Although cohort experiences are generally connected with age-specific period death rates and thus with the estimates of the Gompertz parameter $b$, Equation (2) does not

\footnotetext{
${ }^{9}$ The application of a Gompertz model requires the assumption that mortality under age 30 is negligible since the model does not fit the pattern of mortality in ages below 30. As this assumption is close to reality in modern populations with high life expectancy, it can be accepted as being applicable to western and eastern Germany from 1975 to 2004. However, this method cannot be used in populations with high mortality in infancy, childhood, and young adult ages.

10 Bongaarts and Feeney (2002) fitted the age-specific death rates until age 100. For western and eastern Germany, however, official population and death data for the time series analyzed in this chapter are available only until age 90.
} 
contain a direct cohort component and includes only elements derived from period data.

Table 2 presents the estimates of parameter $\mu_{0}(t)$ and the average of parameter $b$ for the analyzed populations from 1975 to 2004, as done by Bongaarts and Feeney (2002) for the US, Sweden, Japan, and France. The estimates for $b$ for the whole series of single observation years are shown in Tables 3 and 4 , respectively. Corresponding to the observed death rates, $\mu_{0}(t)$ declines over time for all four populations. Similar to what is known for several other countries, the estimated values of $b$ are close to 0.09 among males and 0.10 among females for both western and eastern Germany. During the observation period, the annual estimates of $b$ vary only little over time in each of these populations, as can be seen from the standard deviation of $b$ in Table 2 or from the single values in Tables 3 and 4, respectively. As with the populations analyzed by Bongaarts and Feeney (2002), the Gompertz model fits the observed adult death rates very well, with the average variance explained $\left(R^{2}\right)$ being around 99 percent. This shows that the proportionality (or " constant shape") assumption is approximately valid and the indirect method as introduced by Bongaarts and Feeney (2002) can be applied.

Table 2. Estimates of the parameters of the Gompertz mortality change model, males and females, western and eastern Germany, 1975-2004.

\begin{tabular}{lccccc}
\hline & \multicolumn{2}{c}{ Average $1975-2004$} & & & \\
& $\mu_{0}(1975)$ & $\mu_{0}(2004)$ & $b$ & St. dev. $b$ & $R^{2}$ \\
\hline Western Germany. males & $6.639\left(\cdot 10^{-5}\right)$ & $2.276\left(\cdot 10^{-5}\right)$ & 0.092 & 0.0023 & 0.997 \\
Eastern Germany. males & $4.116\left(\cdot 10^{-5}\right)$ & $2.211\left(\cdot 10^{-5}\right)$ & 0.094 & 0.0029 & 0.994 \\
Western Germany. females & $1.729\left(\cdot 10^{-5}\right)$ & $4.322\left(\cdot 10^{-6}\right)$ & 0.105 & 0.0036 & 0.984 \\
Eastern Germany. females & $1.080\left(\cdot 10^{-5}\right)$ & $4.254\left(\cdot 10^{-6}\right)$ & 0.108 & 0.0043 & 0.991 \\
\hline
\end{tabular}

Based on these data, I used a three-step procedure similar to the procedure proposed by Bongaarts and Feeney (2002). First, I calculated the annual estimates of $e_{0}(t)$ from 1950 to 2004 with life tables that have mortality under age 30 set to 0 . Next, I smoothed the estimates by fitting a sixth degree polynomial, using the computer program Microsoft Excel. The resulting values for the smoothed time series for life expectancy $e_{0}(t)^{S}$ are provided in Tables 3 and 4, respectively. Figure 2 shows the corresponding functions together with the original estimates for $e_{0}(t)$ with no mortality under age 30 . It can be seen that the trends in $e_{30}+30$ (what corresponds to setting mortality below age 30 to 0 ) are very similar to the trends in $e_{0}$, shown in Figure 2. They differ only slightly in the years 1950 to 1970, owing to the fact that mortality below age 30 (and especially infant mortality) had a higher impact on overall life expectancy than it has had in years more recent. Note that the significant decrease in life expectancy at birth $e_{0}(t)$ for East German men in 1990 diminishes in the smoothed values $e_{0}(t)^{S}$. 
To estimate tempo-adjusted life expectancy $e_{0}^{*}(t)$, the original values for $e_{0}(t)$ are substituted by values $e_{0}(t)^{S}$ derived from the polynomial functions. To finally solve Equation (2) for $e_{0}^{*}(t)$, I used the so-called Euler's method, with $S(1950)=2$ as the initial condition for the differential equation. From Equation (1) then follows that $e_{0}^{*}(1950)$ can be directly estimated from $e_{0}(1950)-S(1950)$. For instance, for West German males it follows that $e_{0}^{*}(1950)=71.28-2.00=69.28$. This value represents the assumed tempo distortion for mortality changes until the year 1950, which was equally set for all populations observed, and thus the female and male populations of West and East Germany. The results for the analyzed years after 1975 are not entirely insensitive to this assumed initial condition for the year 1950 but its effect on the estimates is relatively weak ${ }^{11}$. An application of Euler's method leads to an estimate for the tempo-adjusted life expectancy $e_{0}^{*}(1951)$ for the next year from the equation:

$$
e_{0}^{*}(1951)=e_{0}^{*}(1950)+\left\{1-\exp \left[-b(1950)\left(e_{0}(1950)^{S}-e_{0}^{*}(1950)\right)\right]\right\}
$$

or generally written from

$$
e_{0}^{*}(t+1)=e_{0}^{*}(t)+\left\{1-\exp \left[-b(t)\left(e_{0}(t)^{S}-e_{0}^{*}(t)\right)\right]\right\} .
$$

Equation (3) was used to estimate a complete time series of values for tempo-adjusted life expectancy at birth (with no mortality under age 30) until 2004 for western and eastern German females and males. For a more detailed derivation of Equation (3), see Luy (2005a).

\footnotetext{
$\overline{11}$ Setting the initial condition to $S=1$ or $S=3$ causes the estimated West-east German differences in tempo-adjusted life expectancy to deviate from the chosen initial condition $S=2$ by less than 0.01 years for the analyzed years 1975 to 2004; when setting the initial condition to $S=0$ or $S=4$, the deviation does not exceed 0.02 years.
} 
Table 3. Estimates of $e_{0}(t), e_{0}(t)^{S}, b, e_{0}^{*}(t)$, and $S(t)$ for single calendar years, males, western and eastern Germany, 1975-2004 (no mortality under age 30).

\begin{tabular}{|c|c|c|c|c|c|c|c|c|c|c|}
\hline Year & & Wes & Germa & & & & Eas & Germ & & \\
\hline$t$ & $e_{0}(t)$ & $e_{0}(t)^{S}$ & $b$ & $e_{0}^{*}(t)$ & $S(t)$ & $e_{0}(t)$ & $e_{0}(t)^{S}$ & $b$ & $e_{0}^{*}(t)$ & $S(t)$ \\
\hline 1975 & 71.17 & 71.46 & 0.091 & 70.91 & 0.27 & 71.28 & 71.49 & 0.098 & 71.36 & -0.08 \\
\hline 1976 & 71.49 & 71.59 & 0.089 & 70.96 & 0.53 & 71.46 & 71.47 & 0.093 & 71.37 & 0.09 \\
\hline 1977 & 71.96 & 71.73 & 0.090 & 71.01 & 0.95 & 71.59 & 71.44 & 0.094 & 71.38 & 0.21 \\
\hline 1978 & 71.85 & 71.89 & 0.091 & 71.07 & 0.77 & 71.33 & 71.41 & 0.094 & 71.39 & -0.06 \\
\hline 1979 & 72.20 & 72.06 & 0.088 & 71.15 & 1.05 & 71.20 & 71.38 & 0.095 & 71.39 & -0.19 \\
\hline 1980 & 72.29 & 72.23 & 0.088 & 71.22 & 1.07 & 71.07 & 71.35 & 0.097 & 71.39 & -0.31 \\
\hline 1981 & 72.39 & 72.42 & 0.089 & 71.31 & 1.08 & 71.38 & 71.32 & 0.092 & 71.38 & -0.01 \\
\hline 1982 & 72.63 & 72.62 & 0.090 & 71.40 & 1.23 & 71.44 & 71.30 & 0.092 & 71.38 & 0.06 \\
\hline 1983 & 72.78 & 72.82 & 0.089 & 71.51 & 1.27 & 71.66 & 71.28 & 0.093 & 71.37 & 0.29 \\
\hline 1984 & 73.18 & 73.03 & 0.091 & 71.62 & 1.57 & 71.70 & 71.28 & 0.094 & 71.36 & 0.34 \\
\hline 1985 & 73.26 & 73.24 & 0.092 & 71.74 & 1.52 & 71.57 & 71.29 & 0.096 & 71.35 & 0.21 \\
\hline 1986 & 73.54 & 73.45 & 0.091 & 71.87 & 1.67 & 71.51 & 71.33 & 0.095 & 71.35 & 0.16 \\
\hline 1987 & 73.84 & 73.67 & 0.094 & 72.00 & 1.84 & 71.70 & 71.38 & 0.094 & 71.35 & 0.35 \\
\hline 1988 & 74.07 & 73.88 & 0.093 & 72.14 & 1.92 & 71.56 & 71.46 & 0.092 & 71.35 & 0.21 \\
\hline 1989 & 74.13 & 74.09 & 0.094 & 72.29 & 1.84 & 71.88 & 71.57 & 0.093 & 71.36 & 0.52 \\
\hline 1990 & 74.22 & 74.29 & 0.094 & 72.45 & 1.77 & 71.14 & 71.71 & 0.090 & 71.38 & -0.24 \\
\hline 1991 & 74.35 & 74.49 & 0.092 & 72.61 & 1.74 & 71.31 & 71.89 & 0.087 & 71.41 & -0.10 \\
\hline 1992 & 74.68 & 74.69 & 0.091 & 72.77 & 1.91 & 71.77 & 72.10 & 0.090 & 71.45 & 0.32 \\
\hline 1993 & 74.70 & 74.89 & 0.094 & 72.93 & 1.77 & 72.01 & 72.34 & 0.092 & 71.51 & 0.51 \\
\hline 1994 & 74.96 & 75.08 & 0.094 & 73.09 & 1.86 & 72.40 & 72.63 & 0.090 & 71.58 & 0.82 \\
\hline 1995 & 75.05 & 75.27 & 0.092 & 73.26 & 1.78 & 72.81 & 72.95 & 0.094 & 71.67 & 1.14 \\
\hline 1996 & 75.27 & 75.47 & 0.093 & 73.43 & 1.84 & 73.27 & 73.30 & 0.092 & 71.78 & 1.49 \\
\hline 1997 & 75.68 & 75.67 & 0.094 & 73.61 & 2.07 & 73.89 & 73.68 & 0.095 & 71.91 & 1.98 \\
\hline 1998 & 75.99 & 75.89 & 0.094 & 73.78 & 2.21 & 74.43 & 74.08 & 0.095 & 72.07 & 2.37 \\
\hline 1999 & 76.28 & 76.12 & 0.095 & 73.96 & 2.31 & 74.82 & 74.49 & 0.099 & 72.24 & 2.58 \\
\hline 2000 & 76.54 & 76.37 & 0.093 & 74.15 & 2.39 & 75.03 & 74.91 & 0.096 & 72.44 & 2.59 \\
\hline 2001 & 76.93 & 76.66 & 0.095 & 74.33 & 2.60 & 75.52 & 75.32 & 0.096 & 72.65 & 2.87 \\
\hline 2002 & 77.06 & 77.00 & 0.095 & 74.53 & 2.53 & 75.63 & 75.71 & 0.098 & 72.88 & 2.75 \\
\hline 2003 & 77.16 & 77.38 & 0.096 & 74.74 & 2.42 & 75.76 & 76.06 & 0.100 & 73.12 & 2.64 \\
\hline 2004 & 77.76 & 77.84 & 0.096 & 74.96 & 2.80 & 76.33 & 76.34 & 0.099 & 73.37 & 2.96 \\
\hline
\end{tabular}


Table 4. Estimates of $e_{0}(t), e_{0}(t)^{S}, b, e_{0}^{*}(t)$, and $S(t)$ for single calendar years, females, western and eastern Germany, 1975-2004 (no mortality under age 30).

\begin{tabular}{|c|c|c|c|c|c|c|c|c|c|c|}
\hline \multirow{2}{*}{$\begin{array}{c}\text { Year } \\
t\end{array}$} & \multicolumn{5}{|c|}{ West Germany } & \multicolumn{5}{|c|}{ East Germany } \\
\hline & $e_{0}(t)$ & $e_{0}(t)^{S}$ & $b$ & $e_{0}^{*}(t)$ & $S(t)$ & $e_{0}(t)$ & $e_{0}(t)^{S}$ & $b$ & $e_{0}^{*}(t)$ & $S(t)$ \\
\hline 1975 & 76.84 & 77.10 & 0.101 & 75.59 & 1.25 & 75.91 & 76.07 & 0.106 & 75.34 & 0.57 \\
\hline 1976 & 77.17 & 77.28 & 0.100 & 75.73 & 1.43 & 76.15 & 76.10 & 0.105 & 75.41 & 0.73 \\
\hline 1977 & 77.74 & 77.48 & 0.102 & 75.88 & 1.86 & 76.53 & 76.14 & 0.103 & 75.48 & 1.05 \\
\hline 1978 & 77.74 & 77.68 & 0.101 & 76.03 & 1.71 & 76.34 & 76.18 & 0.106 & 75.55 & 0.79 \\
\hline 1979 & 78.03 & 77.89 & 0.099 & 76.18 & 1.85 & 76.40 & 76.23 & 0.106 & 75.61 & 0.79 \\
\hline 1980 & 78.27 & 78.11 & 0.102 & 76.34 & 1.93 & 76.17 & 76.28 & 0.105 & 75.68 & 0.50 \\
\hline 1981 & 78.34 & 78.33 & 0.102 & 76.50 & 1.84 & 76.37 & 76.35 & 0.105 & 75.74 & 0.63 \\
\hline 1982 & 78.57 & 78.56 & 0.102 & 76.67 & 1.90 & 76.57 & 76.43 & 0.105 & 75.80 & 0.77 \\
\hline 1983 & 78.76 & 78.79 & 0.102 & 76.85 & 1.91 & 76.82 & 76.52 & 0.106 & 75.87 & 0.95 \\
\hline 1984 & 79.23 & 79.01 & 0.102 & 77.03 & 2.20 & 76.85 & 76.64 & 0.107 & 75.93 & 0.92 \\
\hline 1985 & 79.30 & 79.24 & 0.104 & 77.21 & 2.09 & 76.77 & 76.77 & 0.107 & 76.01 & 0.76 \\
\hline 1986 & 79.47 & 79.45 & 0.106 & 77.40 & 2.07 & 76.73 & 76.93 & 0.112 & 76.08 & 0.64 \\
\hline 1987 & 79.82 & 79.67 & 0.108 & 77.60 & 2.22 & 77.14 & 77.11 & 0.111 & 76.17 & 0.97 \\
\hline 1988 & 80.02 & 79.87 & 0.105 & 77.80 & 2.22 & 77.17 & 77.31 & 0.108 & 76.27 & 0.90 \\
\hline 1989 & 80.07 & 80.07 & 0.104 & 77.99 & 2.08 & 77.49 & 77.54 & 0.105 & 76.38 & 1.11 \\
\hline 1990 & 80.05 & 80.25 & 0.105 & 78.19 & 1.87 & 77.44 & 77.80 & 0.103 & 76.49 & 0.95 \\
\hline 1991 & 80.26 & 80.43 & 0.106 & 78.38 & 1.87 & 77.69 & 78.09 & 0.101 & 76.62 & 1.07 \\
\hline 1992 & 80.59 & 80.59 & 0.104 & 78.58 & 2.02 & 78.38 & 78.40 & 0.108 & 76.76 & 1.62 \\
\hline 1993 & 80.50 & 80.74 & 0.106 & 78.77 & 1.74 & 78.86 & 78.74 & 0.106 & 76.92 & 1.94 \\
\hline 1994 & 80.78 & 80.89 & 0.107 & 78.96 & 1.82 & 79.18 & 79.10 & 0.118 & 77.10 & 2.08 \\
\hline 1995 & 80.89 & 81.02 & 0.107 & 79.14 & 1.75 & 79.53 & 79.47 & 0.108 & 77.31 & 2.23 \\
\hline 1996 & 80.98 & 81.15 & 0.106 & 79.32 & 1.66 & 79.86 & 79.86 & 0.105 & 77.52 & 2.35 \\
\hline 1997 & 81.32 & 81.29 & 0.108 & 79.50 & 1.82 & 80.43 & 80.26 & 0.115 & 77.73 & 2.69 \\
\hline 1998 & 81.55 & 81.42 & 0.108 & 79.68 & 1.87 & 80.76 & 80.65 & 0.111 & 77.99 & 2.77 \\
\hline 1999 & 81.71 & 81.57 & 0.108 & 79.85 & 1.86 & 81.18 & 81.03 & 0.115 & 78.24 & 2.94 \\
\hline 2000 & 81.93 & 81.74 & 0.108 & 80.02 & 1.91 & 81.47 & 81.39 & 0.113 & 78.52 & 2.95 \\
\hline 2001 & 82.19 & 81.93 & 0.111 & 80.19 & 2.00 & 81.75 & 81.71 & 0.110 & 78.79 & 2.96 \\
\hline 2002 & 82.20 & 82.17 & 0.114 & 80.36 & 1.84 & 81.72 & 81.98 & 0.117 & 79.07 & 2.65 \\
\hline 2003 & 82.21 & 82.46 & 0.112 & 80.55 & 1.66 & 81.97 & 82.18 & 0.115 & 79.36 & 2.61 \\
\hline 2004 & 82.76 & 82.81 & 0.111 & 80.74 & 2.02 & 82.48 & 82.30 & 0.111 & 79.63 & 2.84 \\
\hline
\end{tabular}

